\title{
"Ninguno non puede fazer conde sy le el rrey non le faze". La reescritura del Poema de Fernán González en la Estoria de España como manifestación de la ideología de los cronistas alfonsíes
}

\author{
"Ninguno non puede fazer conde sy le el rrey non le faze" The Estoria de España's \\ rewriting of the Poema de Fernán González's as a manifestation of the ideology of \\ the Alphonsine chroniclers
}

iD Marta Lacomba

mlacomba@u-bordeaux-montaigne.fr

Universidad Bordeaux-Montaigne, Francia

Recepción: 23 Abril 2021

Aprobación: 30 Julio 2021

Publicación: 01 Noviembre 2021

Cita sugerida: Lacomba, M. (2021). "Ninguno non puede fazer conde sy le el rrey non le faze". La reescritura del Poema de Fernán González en la Estoria de España como manifestación de la ideología de los cronistas alfonsíes. Olivar, 21(34), e109. https://doi.org/10.24215/18524478e109

\begin{abstract}
Resumen: En términos generales, la Estoria de España sigue con señalada fidelidad el texto del Poema de Fernán González. Por ello, los puntos de ruptura resultan reveladores de las divergencias ideológicas entre el monje de Arlanza y los cronistas de Alfonso X, cuyo trabajo de reescritura se examina aquí.

Palabras clave: Alfonso X, Poema de Fernán González, Estoria de España, Reescritura, Ideología.

Abstract: In general terms, the Estoria de España follows the text of the Poema de Fernán González with great fidelity. The breaking points are therefore revealing of ideological divergences between the monk of Arlanza and the chroniclers of Alfonso X, whose work of rewriting is examined here.
\end{abstract}

Keywords: Alfonso X, Poema de Fernán González, Estoria de España, Rewriting, Ideology.

El estudio de las crónicas alfonsíes surgió inicialmente como necesidad: para reconstruir los textos de la primigenia épica castellana, Menéndez Pidal recurrió a la huella que estos habían dejado en las crónicas. Como lo señala De la Campa (2009, p. 18), estos primeros trabajos de Menéndez Pidal dejan establecida "la clasificación de las familias de manuscritos cronísticos". Estas observaciones se fueron afinando gracias a los trabajos de otros investigadores; los trabajos de Catalán (1962) determinan así una nueva cronología de los textos, que otorga un lugar central a la Versión Crítica. Esta fue redactada entre 1282 y 1284 y representa una actualización de la Versión Concisa, o Primitiva, de la Estoria de España alfonsí, sobre la que también se basa la Versión de 1289. Como lo han demostrado Catalán (1977 y 1978), Fernández-Ordóñez (1993) y 
De la Campa (2009), la versión llamada "crítica", resulta ser -al menos para ciertas secciones de la Estoria de España - una reescritura llevada a cabo, aún bajo el reinado de Alfonso X, con la voluntad expresa de proporcionar mayor coherencia a la obra. Cabe por otra parte recordar que esta refundición cronística se lleva a cabo en un contexto de crisis y guerra civil provocadas por la rebelión de Sancho, apoyado por gran parte de la nobleza. El rey Sabio, depuesto de su autoridad, potencia en la Versión Crítica una ideología monárquica reforzadora del poder del rey. ${ }^{1}$ De cara a aprehender el núcleo ideológico de los equipos alfonsíes, esta crónica resulta pues la más pertinente, ya que en ella se observa "el perfeccionamiento del texto a través de la crítica interna o la moralización de ciertos pasajes” (De la Campa, 2009, p. 27).

En este trabajo se invierte en cierto modo la motivación de Pidal: se trata de analizar la relación entre épica y crónicas no para reconstituir el modo de creación y el contenido de los cantares de gesta, sino para caracterizar los criterios compositivos de los cronistas. ${ }^{2}$ Se partirá aquí del Poema de Fernán González por la literalidad con que se prosifica en la historiografía alfonsí. Por otra parte, es importante recalcar que "los capítulos que provienen del Poema de Fernán González en la tradición troncal y en la Versión Critica son fruto de una misma compilación" (De la Campa, 2009, p. 176). En efecto, como en el caso de otras fuentes poéticas, la Versión Crítica no recurre de nuevo a estas obras, sino que el proceso de reescritura se hace con respecto al Poema de Fernán González (PFG a partir de ahora) ya compilado, que se combina con elementos procedentes de la obra de Jiménez de Rada:

La Estoria de España toma del Toledano el marco narrativo de la vida del héroe: sus orígenes; su ascenso al poder; el papel que desempeña en las guerras del rey Ramiro II contra los moros; su parte en la sucesión de los reyes Ordoño III y Ramiro III; sus últimas luchas contra los moros, y su muerte. (Pattison, 2003, p. 261)

Del $P F G$, la primera compilación alfonsí incluye en esta estructura ya cronística, los episodios relativos a la lucha contra Almanzor, los enfrentamientos contra el rey Sancho de Navarra, y por último -en una sección que falta en el poema conservado y que por ende no se analizará aquí- "las relaciones del conde con el rey de León, Sancho I, y la independencia del condado de Castilla” (Pattison, 2003, p. 261). Cabe señalar que la fidelidad de la Estoria de España con respecto al $P F G$ es tal que editores como Victorio (1990, pp. 31-32) han utilizado el testimonio cronístico para reconstituir las lagunas del texto poético. En este trabajo, se señalarán las divergencias notables entre la Versión Crítica y la Versión Primitiva de la Estoria de España. ${ }^{3}$

Teniendo en cuenta que los puntos de ruptura entre el texto de la Versión Crítica ( $V C$ a partir de ahora) y el $P F G$ no solo son poco numerosos, sino que presentan una gran coherencia, se tratará aquí de mostrar que la reescritura de esta crónica es reveladora de la ideología, en el sentido amplio del término, de los redactores alfonsíes. Comparando los dos textos en momentos clave, se observa que, con respecto al $P F G$, se alteran los elementos relacionados con la asimilación del conde a una figura regia. Se analizará en un primer tiempo de qué manera opera la $V C$ minimizando la figura de Fernán González en su relación al poder. La segunda parte estará dedicada a la construcción de la figura del héroe con respecto a Dios, también en tonos menores, pues como se verá a través de este prisma se revela la concepción política de los cronistas.

\section{La $V C$ minimiza la figura de Fernán GonzÁlez como gobernante}

En el $P F G$, el héroe accede a la condición de conde por herencia. Tras la muerte de Nuño Rasura, uno de los Jueces de Castilla, se precisa que el hijo de este, Gonzalo Núñez, "anparó bien la tierra, e fizo quanto a podido" (166c). ${ }^{4}$ Gonzalo Núñez tiene tres hijos, Diego, Rodrigo y Fernando, el menor. Al morir los dos mayores, "fincó toda la tierra al ermano menor" (170c), y se precisa dos versos más adelante que "(...) era Castiella un pequeño rincón” (171a). Al quedar asociadas en el relato del poema la posesión de Castilla y la evocación de la línea linajística, a través de las muertes de los antecesores de Fernán González, se establece claramente que este último accede al condado por herencia. 
Por el contrario, la Estoria de España especifica que se trata de una designación: “(...) allegaron se todos los altos omnes et los caualleros e los çibdadanos de Castilla, et alçaron por conde a Ferran Gonçalez" ( $V C$, 274). ${ }^{5}$ Se sigue aquí la versión de los hechos de Jiménez de Rada y la prosificación de la Versión Primitiva (VP desde ahora). ${ }^{6}$ Ahora bien, como lo señala Pattison (2003, p. 262) la $V C$ no solo refiere que Fernán González se convierte en conde por elección, y no por herencia, sino que especifica en otro capítulo que esto motiva la ira de rey Ramiro de León:

El rey don Rramiro non quiso membrar se entonçe del mal que le fizieran los rricos omnes de Castilla en alçar ellos conde syn su mandado, demás que non lo podien fazer de derecho por syse mesmos, ca ninguno non puede fazer conde sy le el rrey non le faze. $(V C, 276)$

Por un lado, la Estoria de España no admite que Fernán González heredara Castilla, sino que afirma que llegó a la cabeza del condado por elección. Por otro, difiriendo aquí de la $V P$ y confirmando la afirmación del poder monárquico de los refundidores de la $V C$, se recalca que este procedimiento no tiene legitimidad, puesto que "ninguno non puede fazer conde sy le el rrey non le faze". ${ }^{7}$ Resulta pues necesario resolver esta situación. Se produce por lo tanto una reconciliación al socorrer el rey a Fernán González y a sus hombres, tras lo cual "los castellanos metieronse estonçe en la mesura del rrey por el conde que fizieran. Et el rrey otorgoles al conde Ferran Gonçales" $(V C, 276)$. Estas dos etapas restablecen el orden en la situación política: el condado de Castilla no se hereda, y aún menos se alcanza por elección, sino que su nominación resulta, como no podía ser de otro modo, de una prerrogativa regia. Esto resulta acorde con lo observado por De la Campa (2009, pp. 129-137) en la cronología y la capitulación de la $V C$ : las alteraciones aportadas con respecto a la $V P$ dan en efecto preeminencia a las acciones del rey Ramiro II sobre las de Fernán González. ${ }^{8}$ La Estoria de España se abre pues a materiales poéticos, pero integrándolos -y por ende reescribiéndolos- en un texto con una clara "función cultural e ideológica de cohesión social" (Funes, 1997, p. 62).

En este mismo sentido, en el relato de la toma de Carazo, que se produce después de la llegada al poder de Fernán González, la $V C$ elimina las menciones que sugieren que el conde realiza esta acción junto a sus hombres. En un fragmento de extensión similar en ambas obras (cuatro estrofas - dieciséis versos - unas ciento quince palabras en el $P F G$, prosificadas en un solo capítulo de la $V C$, el CXXV, de seis líneas y unas cien palabras), desaparecen en efecto las dos menciones de los hombres de Fernán González. ${ }^{9}$ La primera se encuentra en el verso 192c: "moviose con sus gentes, Caraço fue çercar" y resulta en la $V C$ "fue çercar vn castillo que a nombre Caraço" (281). La acción no la realiza el conde junto con sus tropas, sino él solo. En los versos 193a-193b, "El conde castellano, con todos sus varones"/ conbatían las torres a guisa d'infançones", el verbo "combatir" tiene por sujeto al conde y a sus hombres. Al igual que en el ejemplo anterior, en la $V C$ la acción la desarrolla Fernán González como sujeto singular "E conbatiolo tan fuerte $(\ldots)$ " $(V C, 281)$. Cabe subrayar que, en ambos casos, los sintagmas plurales que en el $P F G$ designan a los hombres de Fernán González van introducidos por la preposición "con”, creándose así un fuerte nexo entre el conde y sus subordinados que desaparece en la crónica. Teniendo en cuenta que, como ya se ha señalado, el acceso al condado no había sido refrendado por el rey, se trata de rebajar la estrechez del vínculo entre el conde y sus hombres, minimizando así, en esta primera hazaña, el papel de Fernán González como dirigente.

Se confirma más adelante este retrato del conde en la crónica. La primera mención de los hombres del conde se produce en el capítulo en que Fernán González ve cómo aumentan las huestes de Almanzor: “(...) enbio luego sus cartas por Castilla que viniesen a el luego sus vasallos, que los avié mucho menester" $(V C$, 281). Fernán González no aparece pues aquí como gobernante, sino como jefe militar necesitado de auxilio. Los hombres del conde acuden y, tal y como se les ha pedido, le dan sus consejos. Tras la toma de palabra de Gonzalo Díaz, que se inclina por no presentar batalla frente a las numerosas tropas de Almanzor, Fernán González se muestra descontento. $\mathrm{Si}$, como es habitual, la $V C$ retoma con gran cercanía los versos del $P F G$, incluso cuando se trata de discurso directo, resultan notables las modificaciones operadas sobre el principio y el final de este parlamento, que se recogen en los cuadros siguientes. ${ }^{10}$ 


\begin{tabular}{|l|l|}
\hline \multicolumn{1}{|c|}{$P F G$ (209a- 209d) } & \multicolumn{1}{c|}{$V C(282)$} \\
\hline $\begin{array}{l}\text { Por Dios -dixo el conde- que me querades oir, } \\
\text { quiero a don Gonçalo en todo recudir; } \\
\text { contra quanto a dicho, quiero le yo dezir, } \\
\text { ca tales cosas que dixo ... }\end{array}$ & $\begin{array}{l}\text { Quiero responder a don Gonçalo } \\
\text { e contra quanto el ha dicho }\end{array}$ \\
que sol' non son d'oir. & $\begin{array}{l}\text { que las cosas que aquí mostradas } \\
\text { que sol non son de oyr nin de dezir. }\end{array}$ \\
\hline
\end{tabular}

Cabe destacar que en el $P F G$ se repite tres veces el verbo querer, característico de la voz de mando, puesto que la voluntad del gobernante se explicita para ser realizada. No resultaría pertinente achacar la eliminación de dos de las tres ocurrencias a un afán resumidor (la longitud de ambos fragmentos es similar) o estilístico (la repetición del verbo "decir" se conserva). Si la única ocurrencia de "quiero" en la $V C$ queda en cierto modo destacada por su posición inicial, pierde sin embargo la fuerza que tiene en el verso $209 \mathrm{~b}$ del $P F G$, en que se produce un hipérbaton, quedando el complemento de objeto directo en posición final en el verso ("recudir"), mientras que el "responder" sigue inmediatamente al verbo en la $V C$. El sentido de "quiero" se diluye así en la crónica al pasar a ser verbo auxiliar en una suerte de perífrasis incoativa.

Sin que sea este un relevamiento exhaustivo, he aquí otros ejemplos de este desvanecimiento del querer gonzaliano. El verso $247 \mathrm{~b}$ "quiero todo el mi quinto a este lugar dar" se convierte en "prometo a este lugar todo el mi quinto" (284), y la voluntad explícita de querer morir luchando contra sus enemigos - "querié morir por ver se con moros en el canpo" (254b) - también aparece rebajado ("cudiçiaua ya veer se con moros ayuntado", 286).

Cabe por otra parte recordar que el verbo "querer" aparece en la obra alfonsí claramente asociado a la figura regia, como expresión de su voluntad, decisión y mandato. No solo en la Estoria de España, a través de la manifestación del yo regio en primera persona, sino también en los prólogos de las obras científicas. ${ }^{11}$ A nivel metadiscursivo, puede considerarse que el "querer dezir" constituye en el discurso alfonsí, y en particular en la $V C$, la retícula a través de la cual el rey Sabio trata de imponer su control y su voluntad sobre devenir del reino (Lacomba, 2009, pp. 93-138).

Pasamos ahora a examinar las palabras finales del parlamento en el que Fernán González se dirige a sus hombres, de cara a la batalla contra Almanzor. 


\begin{tabular}{|c|c|}
\hline PFG (221a-224d) ${ }^{1}$ & $V C(283)$ \\
\hline $\begin{array}{l}\text { Dexemos los parientes,... } \\
\text { a lo nuestro tornemos, } \\
\text { por ir a la batalla aquesso aguisemos: } \\
\text { por miedo de la muerte la lid non la escusemos, } \\
\text { caer o levantar, y lo departiremos. }\end{array}$ & $\begin{array}{l}\text { Mas dexemos ahora agora los parientes, } \\
\text { etornemos en lo nuestro; } \\
\text { et guisemos mas para yr a la batalla, } \\
\text { non lo dexemos por miedo de muerte. }\end{array}$ \\
\hline Esforçad castellanos, non hayades pavor, & Ca ayudando nos Dios e nuestra lealtad, \\
\hline $\begin{array}{l}\text { vençremos los poderes d'esse rey Almançor, } \\
\text { sacaremos Castiella de premia e d'error } \\
\text { el será el vençido yo sere el vençedor. }\end{array}$ & $\begin{array}{l}\text { vençeremos a los moros } \\
\text { e sacaremos a Castilla de premia y quebranto. }\end{array}$ \\
\hline $\begin{array}{l}\text { Maguer que muchos son, .... } \\
\text { non valen tres arvejas, }\end{array}$ & $\begin{array}{l}\text { Et no nos deuemos espantar } \\
\text { porque ellos son muchos, }\end{array}$ \\
\hline $\begin{array}{l}\text { mas pueden tres leones que treinta mil golpejas, } \\
\text { irían treinta lobos a treinta mil ovejas. } \\
\text { Amigos, d'una cosa so yo bien sabidor: } \\
\text { que vençremos sin duda al moro Almançor; } \\
\text { de todos los d'España faredes me el mejor: } \\
\text { sera grand la mi onra e la vuestra mayor. }\end{array}$ & $\begin{array}{l}\text { ca mas pueden tres leones que diez mil oveias, } \\
\text { e matarien treinta lobos a treinta mil corderos. } \\
\text { E amigos, sed çiertos } \\
\text { que nos vençremos a Almançor de aquesta vez, } \\
\text { [e faredes de mi el mejor omne de España] } \\
\text { e será grande la mi onrra e la vuestra mayor, } \\
\text { e faredes de mi el mejor omne de España. }\end{array}$ \\
\hline
\end{tabular}

Se puede comprobar que estas palabras finales siguen en la crónica con gran fidelidad la gran mayoría de lo que dice el héroe en el $P F G$, con lo cual resultan patentes las modificaciones operadas. ${ }^{13}$ En primer lugar, desaparecen tanto las órdenes directas, a través del imperativo, ("esforçad", "non hayades", 222a) que el conde les da a sus hombres, como el vocativo con que se dirige a ellos ("castellanos", 222a). Esto resulta totalmente acorde con lo anteriormente observado, a saber la minoración de la voluntad y del imperio del héroe. Se escamotea así la relación directa, a través de la capacidad de mando, entre Fernán González y sus hombres. En este punto, la $V C$ añade unas palabras harto reveladoras (en cursiva en el cuadro), que vienen a cubrir la voz imperante del conde: "Ca ayudando nos Dios e nuestra lealtad". El resultado es el mismo en ambos textos -tanto tras la arenga del poema como tras estas palabras, Fernán González afirma que "vençremos los poderes d'esse rey Almançor" ( $P F G, 224 \mathrm{~b})$ / "vençeremos a los moros” $(V C, 283)$. Ahora bien, en el caso de la crónica la victoria ya no depende de la capacidad de mando del héroe, sino de la ayuda divina y de la lealtad humana. Como lo señala González-Casanovas (1993, p. 278), en la Estoria de España, "el énfasis (...) cae no en la fuerza de hombres de la frontera sino en la lealtad de nobles de la corte".

De la misma manera, se producen dos transformaciones de la estrofa 224 que corroboran esta interpretación. La primera, al igual que el "quiero" y los imperativos, desaparece aquí la manifestación explícita del "yo". Del “so yo bien sabidor" (224a) se pasa al "sed çiertos”. Una vez más, la consecuencia de esa certeza es la misma en ambas obras: "vençremos sin duda al moro Almançor" (224b) / "que nos vençremos 
a Almançor". Una victoria colectiva, como lo demuestra el uso de la primera persona del plural. Este es el aspecto que enfatiza la $V C$ a través del cambio de orden que se produce con respecto a los últimos versos de este parlamento. En el $P F G$, tras la certeza de la victoria se afirma: "de todos los d'España faredes me el mejor: / sera grand la mi onra e la vuestra mayor" (224c-224d). La honra del héroe parece pues derivar por supuesto de la victoria pero también, y así queda sintácticamente afirmado, de la relación con sus hombres, que lo lleva a ser el "mejor". Sobreentendiéndose el mejor líder. La crónica conserva ambos conceptos, se celebran tanto la grandeza como la honra de Fernán González. Pero, al modificar el orden de los factores, se altera asimismo el resultado semántico: "e será grande la mi onrra e la vuestra mayor, e faredes de mi el mejor omne de España". La ilación que aquí se presenta convierte a la honra del conde, y de sus hombres, una mera consecuencia de la victoria frente a Almanzor, y de esta victoria viene la grandeza, que pierde aquí todo carácter político ya que se limita tan solo a lo militar.

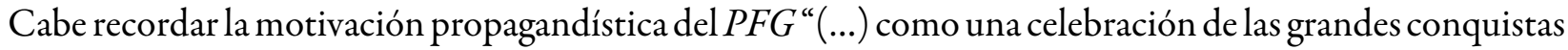
territoriales de Fernando y como un deseo programático para el incipiente reinado de Alfonso" (Fuentes, 2017, p. 440). Ahora bien, esta asimilación entre el conde de Castilla y una figura regia resulta sin duda excesiva para los compiladores alfonsíes. De ahí que, como se ha mostrado, los cronistas de la $V C$ intervengan haciendo desaparecer los elementos que asocian a Fernán González con las funciones de gobierno.

\section{LA $V C$ MODIFICA EL ENMARQUE DEL VÍNCULO CON LO DIVINO}

En el $P F G$, el conde de Castilla aparece en gran medida como un cruzado al servicio de la guerra santa, lo cual afirma indirectamente la preeminencia de la sumisión a Dios con respecto a cualquier otro poder terrenal. Se tratará de determinar a continuación que estos dos elementos se encuadran de manera diferente en la $V C$.

Tras la batalla de Lara y la victoria de los castellanos, el $P F G$ vincula en dos ocasiones explícitamente a Dios con el botín obtenido al huir precipitadamente las tropas de Almanzor de su campamento. Se trata de los versos 275b, "cojieron sus averes que Dios les avie dado", y 281a, "de toda su ganancia que Dios les avie dado". La $V C(286)$ y la $V P(702)$ tan solo mencionan el enriquecimiento de "todos". Desaparece, en ambos casos, el nexo entre la generosidad divina y los bienes de guerra diluyéndose de esta forma el carácter sagrado de las victorias de Fernán González.

Antes de la batalla de Hacinas, el conde reza a Dios para pedirle su ayuda. Al inicio de esta oración, Fernán González reitera en el poema su compromiso cristiano con respecto a Dios. Esta religiosidad también queda recogida -de manera casi literal- en la $V C$ pero de forma ligeramente atenuada, como se observa en el cuadro siguiente:

\begin{tabular}{|l|l|}
\hline \multicolumn{1}{|c|}{ PFG (395a-395d) } & \multicolumn{1}{c|}{$V C(297)$} \\
\hline $\begin{array}{l}\text { Señor, por grand amor de fer a ti servicio, } \\
\text { passo mucho lazerio e dexo mucho viçio, } \\
\text { con est' cuerpo lazrado fago te sacrificio, } \\
\begin{array}{l}\text { con moros e cristianos meto me en grand } \\
\text { bolliçio. }\end{array}\end{array}$ & $\begin{array}{l}\text { Señor, con grand amor de seruir a ty } \\
\text { sufro yo mucha lazeria e dexo mucho viçio }\end{array}$ \\
\hline
\end{tabular}

Así, de los cinco elementos que el héroe del poema ofrece a Dios o acepta por Él, amor, servicio, padecimiento, sacrificio y enemistad con sus contemporáneos, la $V C$ elimina el sacrificio y la mención del sufrimiento corporal explícito que recoge el verso 395c. ${ }^{14}$ Esta ofrenda máxima, que evoca prácticas martiriales, no tiene cabida en la crónica, que rebaja pues tanto la implicación exacerbada del conde con respecto a Dios como el carácter cruzado de su lucha. 
En esta misma oración, para implorar de nuevo el auxilio divino, Fernán González evoca, en el $P F G$, la ayuda recibida en la batalla de Lara. La intervención de Dios en esa ocasión aparece como un acto de voluntad: "quesiste tú, Señor, valer me e ayudar" (400d). En la $V C$ (así como en la $V P, 709)$ el verbo "querer" desaparece y tan solo se consigna el resultado: "Señor, con la tu merçed e con la tu ayuda vençi al moro Almançor” (297). El conde de Castilla no se presenta pues aquí bajo los rasgos del elegido divino, a favor del cual Dios interviene consciente y activamente, como es el caso en el $P F G$.

En este mismo fragmento, se reduce de nuevo el vínculo que en el poema establece el héroe con la divinidad. En el $P F G$, Fernán González afirma estar al servicio de Dios como caudillo al frente de una guerra santa ("Señor, tu siervo so con mis cavallerias", 402c). Esto parece sugerir en cierto modo una relación de reciprocidad, en la cual cabe esperar una respuesta divina: "Mas yo he grand mester, Señor, de la tu ayuda" (403a). Todas las expresiones clave de dos versos, aquellas que establecen un vínculo privilegiado entre Fernán González y Dios, desaparecen totalmente de la $V C$ (que sigue aquí la $V P, 709$ ). La primera, "tu siervo so con mis cavallerias", se convierte en un suave "fazer a ti servicio". La segunda, la necesidad, el "mester" que implicaría la intervención divina se vuelve aquí un simple ruego "pido te merced que aya la tu ayuda" ( $V C$ 297 y VP 709). De la misma manera, para forzar en cierto modo el auxilio de Dios, el conde afirma en el $P F G$ que solo Dios puede salvar a Castilla, lo cual aparece de una manera bien distinta en la $V C$ :

\begin{tabular}{|l|l|}
\hline \multicolumn{1}{|c|}{$P F G$ (403b-403d) } & \multicolumn{1}{c|}{ VC (297) } \\
\hline $\begin{array}{l}\text { Señor, sea por ti Castiella defenduda, } \\
\text { toda tierra de Africa sobre mi es venuda, } \\
\text { anparar non la puedo, Señor, sin la tu ayuda. }\end{array}$ & $\begin{array}{l}\text { pido te }(. . .) \text { que defiendas a Castilla } \\
\text { ca toda la tierra de Africa es sobre mi venida, } \\
\end{array}$ \\
& $\begin{array}{l}\text { e que me des seso e esfuerço por que yo vença } \\
\text { al moro Almançor e todo su poder. }\end{array}$ \\
\hline
\end{tabular}

La $V C$ conserva la petición de ayuda pero elimina la presión ejercida a través del verso 403d, en que el héroe viene a sugerir que, sin intervención divina, Castilla está perdida, situando así la batalla entre cristianos y musulmanes en un plano transcendente. Frente a esto, la crónica opta por afirmar por el contrario que las batallas se juegan en el ámbito estrictamente humano, como lo demuestran las ocurrencias de "seso" y "esfuerço": eso le pide a Dios el Fernán González alfonsí para alcanzar la victoria.

Fernán González es pues en la $V C$ un excelente guerrero, que vence por sus cualidades militares y que reza para obtener el amparo de Dios, pero se omiten los elementos que hacen de él un elegido. Así, en el $P F G$, la batalla contra Almanzor aparece de manera explícita como una misión encomendada directamente por Dios: "manda te que te vayas lidiar con Almançor" (409d). Esto desaparece por completo de la crónica. Un poco más adelante, el monje Pelayo se aparece en sueños al héroe, anunciándole el socorro divino para la batalla. En el $P F G$, el monje le asegura que él mismo acudirá a la batalla, junto con el apóstol Santiago, ya que "enviar nos ha Cristo a valer a su criado" (410c). Las menciones de "criado" y "Señor”, prueba del estrecho vínculo que se establece en el $P F G$ entre el héroe y Dios, desaparecen en la $V C$ que las sustituye por "e le fazes seruiçio de coraçon" (297). ${ }^{15}$ Como lo señala González-Casanovas (1993, p. 278), el PFG destaca "la milicia de Cristo sobre la jerarquía de cualquier corte civilizada”, mientras que en la Estoria de España:

(...) quedan integrados los valores de la moralidad humana y la legitimidad de la clase gobernante al hacer el bien por deber y escoger lo mejor por política; se restablece el orden temporal de la sociedad de la corte. (González-Casanovas, 1993, p. 279)

En la reescritura que la $V C$ opera sobre el $P F G$ se diluye pues en el vínculo entre Dios y el héroe, lo cual conlleva una modificación de los parámetros relativos a la relación entre Dios y los gobernantes, como se mostrará a través del análisis comparativo de varios episodios. 
Al verse señor de Castilla, Fernán González le reza a Dios para que este le permita desempeñar esa función lo mejor posible. Sus palabras ocupan en el $P F G$ veintidós versos (185c-190d) y representan unas ciento setenta y seis palabras. Esta oración queda recogida en la $V C$, también en discurso directo, y ocupa un espacio sensiblemente equivalente al de la fuente poética, diez líneas en la edición citada, lo que corresponde a unas ciento setenta palabras. Ahora bien, a pesar de que tanto cuantitativa como cualitativamente se observa una gran fidelidad de la crónica con respecto al poema, se reduce considerablemente el número de menciones del vocativo "Señor". Las ocho ocurrencias del $P F G$ pasan a ser en la $V C$ tan solo cuatro. Asimismo, desaparece el vocativo "Rey de Reyes", referido obviamente a Dios. Los versos que contienen esta expresión no aparecen de hecho prosificados de la $V C$ (así como tampoco lo estaban en la $V P, 695$ ), tal y como aparece en el siguiente cuadro. ${ }^{16}$

\begin{tabular}{|l|l|}
\hline \multicolumn{1}{|c|}{$P F G(187 a-188 a)$} & \multicolumn{1}{|c|}{ VC (p. 275) } \\
\hline $\begin{array}{l}\text { Señor, } \\
\text { ha luengo tiempo que viven mala vida, } \\
\text { son mucho apremiados } \\
\text { de la gent descreida; }\end{array}$ & $\begin{array}{l}\text { (...) señor, } \\
\text { luengo tiempo a que biuen } \\
\text { mucho apremiados e mucho quebrantados } \\
\text { de los moros. }\end{array}$ \\
$\begin{array}{l}\text { Señor, Rey de los Reyes, aya la tu ayuda, } \\
\text { que yo tome a Castiella a la buena medida. }\end{array}$ & \\
$\begin{array}{l}\text { Si por alguna culpa cayermos en tu saña, } \\
\text { (...). }\end{array}$ & $\begin{array}{l}\text { E sy por alguna nuestra culpa caymos nos en tu } \\
\text { yra, (...) }\end{array}$ \\
\hline
\end{tabular}

No se trata de una modificación casual, puesto que se vuelve a producir más adelante. Al referir Fernán González cómo oyó la voz de san Millán, el $P F G$ vuelve a utilizar el sintagma "rey de Reyes", y, de nuevo, la $V C$ (como antes la $V P, 709)$ lo desestima: 


\begin{tabular}{|c|c|}
\hline$P F G(428 \mathrm{c}-430 \mathrm{c})$ & VC (p. 298) \\
\hline $\begin{array}{l}\text { (...) oi una grand voz del çielo desçender, } \\
\text { voz era de los santos } \\
\text { segun mi entender. } \\
\text { Esta es la razón que la voz me dezia: } \\
\text { "Conde Fernan Gonzalez, lieva dend", ve tu via, } \\
\text { todo el poder de Africa e del Andaluzia } \\
\text { vençer lo has en el canpo d'este terçero dia." } \\
\text { Dixo m' que mal fazia por tanto que tardava } \\
\text { a aquel Rey de los Reyes } \\
\text { por cuya amor lidiava, } \\
\text { que fuesse e non tardasse contra la gent } \\
\text { pagana, } \\
\text { que por que avie miedo, pues que el } \\
\text { me avudava. }\end{array}$ & $\begin{array}{l}\text { segund el mio entender, } \\
\text { que dixo asy: } \\
\text { "Conde Ferran Gonçales, lieuate e vete tu via, } \\
\text { ca desde tercer o dia vençeras Almancọr e a } \\
\text { todo su poder", } \\
\text { e que fazia mal en tardar tanto, } \\
\text { ca aquel } \\
\text { por cuyo amor lidiaua }\end{array}$ \\
\hline
\end{tabular}

Como lo señala Cartelet (2016), “aquel Rey de los Reyes (...) se vuelve un mero aquel”. Al desaparecer el sustantivo, "aquel" ya no es adjetivo demostrativo sino que pasa a ser pronombre. Por segunda vez, la VC omite el sintagma "Rey de los Reyes", lo cual confirma que este no casa con los planteamientos de los cronistas alfonsíes.

De igual manera, se producen una serie de elisiones o transformaciones que hallan su razón de ser en el marcado cariz político que se le atribuye en el $P F G$ al vínculo entre Fernán González y Dios. Como apunta Bailey (1993, p. 88), “These omissions suggest a reluctance to represent Fernán González as an entirely dependent vassal of God (...). Según se afirma explícitamente en una de las profecías, la relación que los une los coloca en las posiciones de vasallo y señor: "que tu eres su vassallo e el es tu Señor" (409b). La $V C$ modifica el final de este verso: "E avn te dize mas Nuestro Señor: que por que tu eres su uasallo, e le fazes seruiçio de coraçon, que te enbiara al apostol Santiago (...)” (VC 297 y VP 709). No se trata tan solo de la desaparición del término "Señor", que cobraba en el poema un carácter político, al aparecer como correlato de "vasallo", sino que la modificación de la sintaxis de la frase altera por completo su alcance. En el $P F G$ la estructura "pronombre + cópula + adjetivo posesivo + atributo" se duplica, unida por el ilativo "e", y a la vez se cierra sobre sí misma, al ser el sujeto de la segunda proposición la persona a la que se refiere el posesivo de la primera y recíprocamente. No se trata pues tan solo de la desaparición del término "Señor", sino que también se rompe en la $V C$ la manifestación sintáctica de la estrechez del vínculo. Por otra parte, en el poema, estas dos proposiciones atributivas enlazadas se bastan a sí mismas y son constituyentes de sentido. En la $V C$, la segunda es una simple proposición causal (puesto que Fernán González es vasallo de Dios y está a su servicio) que entraña una consecuencia (recibirá la ayuda divina).

Se trata pues, en la prosificación cronística, de minimizar los elementos que parecen colocar a Dios por encima del señor terrenal, del rey, a quien debe vasallaje humano el conde. Así cabe explicar la eliminación de todo un fragmento -algo muy poco usual- del $P F G$ en la Estoria de España (ya presente en la VP, 709). Se trata de parte de un parlamento de Fernán González en que este se dirige a sus hombres antes de la batalla contra Almanzor. Se puede observar que antes y después de los versos no prosificados, la $V C$ sigue fielmente el contenido del poema: 


\begin{tabular}{|c|c|}
\hline PFG 440a - 445a & $V C(298)$ \\
\hline $\begin{array}{l}\text { Ligera cosa es la muerte de pasar, } \\
\text { muerte de cada dia muy mala es d'endurar, } \\
\text { sofrir tanto lazerio e ver tanto pesar, } \\
\text { ver los sus enemigos lo suyo heredar. } \\
\text { Conteçe eso mismo con la gent renegada, } \\
\text { heredan nuestra tierra e tienen la forçada; } \\
\text { endreçar se ha la rueda que esta trestornada, } \\
\text { serán ellos vençidos, de Cristo la fe onrada. } \\
\text { Non es dicha fortuna por sienpre en un estado, } \\
\text { uno ser sienpre rico e otro ser menguado, } \\
\text { camia estas dos cosas la fortuna priado, } \\
\text { al pobre faze rico e al rico menguado. } \\
\text { Quiere fazer las cossas assi el Criador, } \\
\text { de dar e de quitar el es el fazedor } \\
\text { por entender que el es sobre todos mejor; } \\
\text { el que suel' ser vençido será el vençedor. } \\
\text { A tal Señor commo este devemos nos rogar, } \\
\text { que por la su mesura nos quiera ayudar, } \\
\text { que en el nos esta todo, caer o levantar, } \\
\text { ca sin el non podemos nulla cosa acabar. }\end{array}$ & $\begin{array}{l}\text { (...) querrie mas la muerte que non la vida } \\
\text { demas veer lo suyo heredar a sus enemigos. }\end{array}$ \\
\hline Amigos, lo que digo bien entender devedes. & $\begin{array}{l}\text { Amigos lo que vos yo digo todos vos lo } \\
\text { entendedes. }\end{array}$ \\
\hline
\end{tabular}

En el largo fragmento que desaparece en la crónica, se subraya por un lado el poder de la fortuna, cuya rueda muda la vida de los hombres, y por otro el de Cristo, el "fazedor" que es "sobre todos mejor" y sin quien nada se puede "acabar". Estas estrofas, que constituyen una afirmación de todo aquello que queda fuera del alcance de imperio y de la voluntad de los hombres, y por lo tanto del poder del rey, no podían en efecto tener cabida en una obra cuya ideología está marcada por los conceptos de señorío y de naturaleza.

Así se explica también la desaparición de las dos ocurrencias de "quiero" en la prosificación de las palabras proféticas proferidas en el poema durante la aparición del monje Pelayo. De la primera es sujeto Dios, "que quiere tu fazienda guiar el Criador" (237c), de la segunda el propio monje, "Non quiero mas dezir te de toda tu andança” (239a). En la crónica, sin bien se mantiene el sentido de las palabras, desaparece la expresión de la voluntad y de la determinación que transmite el verbo "querer": “(...) que guiará Dios tu fazienda” ( $V C$, 284; $V P, 701)$. En el caso del "non quiero" del monje, en cierto modo más retórico, se suprime y se pasa directamente a precisar cuál será esa "buena andança” anunciada: “(...) que por todo el mundo sera sonada la tu gran caualleria" ( $V C, 284 ; \mathrm{VP}, 701)$.

Se está pues jugando, a través de la relación entre Fernán González y Dios, el fundamento mismo de la legitimidad de la figura regia con respecto a sus vasallos. Cabe en este punto volver a la expresión "Rey de 
Reyes", que en dos ocasiones se elimina en la reescritura de la $V C$, ya que resulta acorde con lo observado en las fuentes jurídicas y por ende cobra gran importancia con respecto al punto que ahora nos ocupa. Sobre la cuestión de la relación con la divinidad, Panateri (2017, pp. 172-182) hace unas observaciones clave respecto al uso diferenciado de Cristo y Dios en el discurso alfonsí. En particular, este autor establece que mientras que la Iglesia y los miembros del clero son vicarios de Cristo, tan solo el rey es vicario de Dios puesto que "El rey es puesto en la tierra en lugar de Dios" (P. II, I, 5):

En rigor, la Iglesia es vicaria de Cristo pues, al igual que Él, comienza en un determinado momento que puede ser datado (...). Dios es el rey mismo y, por tanto, reinando sobre la creación, la institución regia se encontraría desde el punto cero del mundo. (Panateri, 2017, p. 180)

En esta configuración, la legitimidad del rey es anterior a la de cualquier otra institución, pues procede de la de Dios, que es “rey sobre todos los reyes". Queda así puesto de manifiesto el vínculo entre la expresión "rey de reyes" y la figura regia, y resulta coherente que se desestime su uso por parte del conde Fernán González en la $V C$. Se destaca asimismo la existencia de una misma y única ideología en los redactores alfonsíes, que trasciende las fronteras entre derecho y crónicas.

\section{CONCLUSIÓN}

Se ha examinado en este trabajo cómo, a través de coherentes eliminaciones y reescrituras, se modifica en la $V C$ la figura del conde de Castilla, en su doble faceta de gobernante y de elegido de Dios. Ahora bien, cabe señalar que en la prosificación del $P F G$ también se encuentran interpolaciones que no son sino la expresión del pensamiento político alfonsí. Es lo que se produce en el episodio del caballo y del azor, cuya venta al rey de León llevan en la leyenda a la independencia de Castilla. Es necesario destacar que se trata de uno de los episodios que tiene en el poema mayor carga contra la figura y la institución regia. En él, y por dar tan solo ejemplo, la voz narrativa afirma que el conde es reacio a acudir a las cortes convocadas por el rey: "Ovo ir a Cortes pero con grand pesar, / era muy fiera cosa la mano le besar" (571ab). Queda claramente expresada la resistencia al besamanos, símbolo de la relación entre vasallo y señor. En la $V C$, que difiere aquí de la $V P$ (720), se inserta en este punto una larga interpolación en la cual se expone la primacía del señor natural y la importancia de los buenos consejeros. Interesa destacar aquí un corto fragmento cuyo sentido es radicalmente opuesto al de las palabras atribuidas por la voz poética al conde en el $P F G$, y que queda recalcado al ponerse en la crónica en boca de Fernán González:

Et el rrey de Leon me ha enviado dezir por sus cartas que vaya a sus cortes o sy non quel de el condado, e yo quiero gelo dar, ca non serie derecho de gelo tener por fuerça (...). De mas que non so yo omne de alçar me con tierra, et los castellanos non suelen tales fechos commo estos fazer; esta es vna de las mayores maldades del mundo alçar se ningun omne con tierra a señor, e podrie ser rrebtado por traydor quien quier que lo fiziese (...). $(V C, 317)$

El discurso político se torna moral, ya que se trata de una sola y misma cosa en la mentalidad alfonsí. Como se puede observar, lo que aquí se explicita son precisamente las motivaciones que sustentan las omisiones y atenuaciones que se han venido analizando. Por un lado, se elimina todo aquello que redunda en el $P F G$ en atribuir al conde características que puedan entrar a rivalizar con las de la realeza, o en poner su relación con Dios por encima del vínculo de naturaleza.

La $V C$, redactada en contra de la revuelta aristocrática, explicita aquí la doctrina política alfonsí. Esto no significa que todas las intervenciones antes analizadas se realizaran de forma consciente: en mi opinión, resultan demasiado coherentes como para serlo. No considero que se trate de una reescritura en términos de "censura", sino de una adaptación fluida. Mi hipótesis es que los equipos alfonsíes estaban tan imbuidos y convencidos del proyecto en que participan que los retoques al $P F G$ resultan tan sistemáticos precisamente por no ser conscientes sino por resultar y ser consecuencia de verdaderas creencias compartidas. Tan solo 
en los momentos en los que el poema expresa valores absolutamente contrarios a los preconizados por los cronistas, emerge de forma afirmativa su propio discurso.

Era sin duda necesario, a los ojos de los compiladores alfonsíes, desarticular el ideal imperial que nutre la construcción del héroe en la obra del monje de Arlanza, basada en el vínculo que se establece entre el conde de Castilla y el padre de Alfonso X:

la coincidencia de nombres y de cualidades guerreras y piadosas entre Fernán González y Fernando III en torno a Castilla, reales o inventadas, es con toda probabilidad uno de los motivos principales por los que el monje eligió el tema del poema. (Moreno Hernández, 2000, p. 464)

Los rasgos que tienden a asimilar la figura del conde de Castilla con la del rey santo han sido difuminados en la crónica alfonsí. En la $V C$, se conservan los hechos y las hazañas del conde de Castilla, pero superponiéndoles un nuevo patrón interpretativo, que hace aparecer una suerte de retrato de intaglio de la figura regia.

\section{REFERENCIAS}

Bailey, M. (1993). The Poema del Cid and the Poema de Fernán González: The Transformation of an Epic Tradition. Madison: Hispanic Seminary of Medieval Studies.

Catalán, D. (1962). De Alfonso X al conde de Barcelos. Cuatro estudios sobre el nacimiento de la historiografía romance en Castilla y Portugal. Madrid: Gredos.

Catalán, D. (1977). Don Juan Manuel ante el modelo alfonsí, el testimonio de la Crónica Abreviada. En I. Macpherson (ed.), Juan Manuel Studies. Londres: Tamesis.

Catalán, D. (1978). Los modos de producción y de 'reproducción' del texto literario y la noción de apertura. En Homenaje a Julio Caro Baroja. Madrid: CSIC.

Cartelet, P. (2016). Capítulo III. La integración de la profecía bíblica en el contexto cronístico: el papel religiosopolítico de las profecías en la Estoria de España In: 'Fágote de tanto sabidor'. La construcción del motivo profético en la literatura medieval hispánica (siglos XIII-XV) [en línea]. París: e-Spania Books (http://books.openeditio n.org/esb/1038).

De la Campa, M. (2009). La Estoria de España de Alfonso X: estudio y edición de la "Versión crítica" desde Fruela II hasta la muerte de Fernando II. Málaga: Analecta Malacitana.

Fernández-Ordoñez, I. (1993). "Versión Crítica" de la Estoria de España: Estudio y edición desde Pelayo hasta Ortoño II. Madrid: Fundación Ramón Menéndez Pidal-Universidad Autónoma de Madrid.

Fuentes, M. (2017). El Poema de Fernán González y el imperialismo castellano del siglo XIII. eHumanista: Journal of Iberian Studies, 35, 439-453.

Funes, L. (1997). El modelo historiográfico alfonsi: una caracterización. Londres: Queen Mary and Westfield College.

González-Casanovas, R.J. (1993). La recepción ejemplar de Fernán González en épica y crónica. En A. A. Nascimento, C. Almeida Ribeiro (Ed.), Actas do IV Congresso da Associaçâo Hispânica de Literatura Medieval (pp. 275-281). Lisboa: Ediçoes Cosmos, vol. 4.

Lacomba, M. (2009). Au-delà du Cantar de Mio Cid. Les épigones de la geste cidienne à la fin du XIIIe siècle. Madrid: Casa de Velázquez.

Lacomba, M. (2010). Réécriture et traduction dans le discours d'Alphonse X, Cahiers d'études hispaniques médiévales, $33,27-42$.

Lacomba, M. (2011). El saber alfonsí frente a sus modelos. El caso del saber natural, a través del Libro de los Iudizios », en Luis González Fernández (ed.), Hommage à André Gallego : La transmission de savoirs licites ou illicites dans le monde hispanique péninsulaire (XIIe au XVIIe siècles). (pp. 79-92) Toulouse: Université de Toulouse le Mirail (col. Méridiennes: Études Médiévales Ibériques).

Lacomba, M. (2014). La opinión del consejero en las obras de Alfonso X: función ideal y papel real », in Martine Charageat (Ed.), Consulter les Juges au Moyen Âge, juger, décider. Le rôle de l'avis dans le processus décisionnel 
médiéval (pp. 167-187). Toulouse: Université de Toulouse-Le Mirail (col. Méridiennes : Études Médiévales Ibériques).

Moreno Hernández, C. (2000). Raíces medievales del nacional catolicismo: El Poema de Fernán González. Anuario de estudios medievales, (30)1, 451-470.

Panateri, D. (2017). El discurso del rey. El discurso jurídico alfonsi y sus implicancias políticas. Madrid: Universidad Carlos III.

Pattison D. (2003). Los equipos alfonsíes y post-alfonsíes frente a Jiménez de Rada: problemas y soluciones. Cahiers de linguistique et de civilisation hispaniques médiévales, 26, 259-266.

Victorio J. (ed.) (1990). Poema de Fernán González. Madrid: Cátedra.

Ward A. (ed.) (2016), Estoria de Espanna Digital v.1.0. Birmingham: University of Birmingham. Recuperado de estoria.bham.ac.uk

\section{Notas}

$1 \mathrm{Al}$ morir el primogénito y heredero de Alfonso en 1275, se produce un conflicto entre el derecho consuetudinario castellano, que ante este tipo de situación preveía que el reino debía pasar al segundogénito, en este caso Sancho. Sin embargo, las Siete Partidas, elaboradas en base al derecho romano, reconocían el derecho de representación (ius representationis) y por ende el sucesor debía ser Alfonso, el hijo mayor de Fernando, llamado de la Cerda. Si bien el rey, en contra del código por él mismo redactado, se inclinó en 1278 por reconocer a su hijo Sancho como heredero, esto no fue suficiente. En efecto, en parte como respuesta a las presiones del rey de Francia, Felipe III, tío de Alfonso de la Cerda, Alfonso X decidió crear un reino en Jaén para su nieto. En 1282, Sancho se niega a aceptar esta amputación de los territorios de su herencia, y a él se suma buena parte de la nobleza, descontenta de la política fiscal y jurídica del rey. Sancho organiza unas cortes en Valladolid, que desposeen de todas sus atribuciones como monarca, excepto del título real, a Alfonso X.

2 Esta cuestión ha sido abordada por autores con objetivos diferentes, como establecer las diferencias expresivas entre el Poema de mio Cid y el Poema de Fernán González (Bailey, 1993), examinar el carácter historicista de la ejemplaridad del conde de Castilla (González-Casanovas, 1993) o analizar el valor y sentido de la profecía, en el marco de la literatura medieval hispana (Cartelet, 2016).

3 Las citas de la Versión Primitiva corresponden a la paginación de la "versión primitiva editada" de Ward (2016).

4 Se cita el PFG según la edición de Victorio (1990).

5 Las citas de la Estoria de España corresponden al número de página de la "Versión crítica", (VC) en la edición de De la Campa.

6 En este caso, el texto de la VP no difiere del de la VC: "Ouieron su conseio los ricos omnes e los caualleros de castiella de alçar por conde aferrant gonçales fijo de gonçalo nunnez” (VP, 695).

7 La VP tan solo expresa el juicio negativo sobre los "ricos omnes" de Castilla, pero no expresa ninguna doctrina política: "El Rey don Ramiro quando lo oyo non se quiso membrar del mal quel fizieran los Ricos omnes de castiella e saco luego su hueste muy grant e fue ayudar al conde ferrant gonçales e ayuntaronse amos ados e sacaron sus huestes la del Rey e la delos castellanos en uno e fueron contra los castellanos que eran en Osma" (VP, 697).

8 De la Campa (2009, pp. 129-137) ha mostrado que, en algunos capítulos de la historia de Fernán González, la "Versión Crítica" modifica la trama cronológica heredada de la "Versión Troncal" para dotar de mayor "coherencia al nuevo relato que estaba montando (idem, p. 135), proponiendo asimismo una reescritura y actualización léxica y estilística (idem, pp. 176-182).

9 Ya era el caso en la $V P(699-700)$.

10 Para hacer patente la fidelidad de la VC al texto del PFG y hacer aparecer las rupturas, no se respeta tipográficamente la estructura versal, sino que se indica dicha continuidad a través del signo /.

11 Cabe citar, a modo de ejemplo, el "quiero" de Fernando I en la VC durante el episodio de la partición de los reinos, "quiero vos rrogar que me otorguedes lo que yo quiero agora hacer" (416); "ante que muera quiero partyr los rregnos a mis fijos" (417) (Lacomba, 2014, p. 174). Del mismo modo, los prólogos están repletos de verbos como "mandamos", “compusiemos", "fezimos", etc. (Lacomba, 2010, p. 37). Por otra parte, esta capacidad de voluntad y de creación aparece como una característica tanto del rey como de Dios, afirmada no solo en los contenidos sino también a través de la sintaxis, en particular en el prólogo del Libro conplido en los Iudizios de las Estrellas (Lacomba, 2011, pp. 88-91).

12 Se produce en este punto una pequeña laguna en el $P F G$ (Victorio, 1990, 91).

13 Todas las trasformaciones operadas sobre la estrofa 224 se encontraban ya en la Versión Primitiva (700). 
14 La VC es aquí conforme a la $V P(709)$.

$15 V P, 709$.

16 Como ya se ha precisado, el objetivo del cuadro es hacer patentes las semejanzas y las diferencias, por lo cual no se respeta la disposición tipográfica de los textos. 